\title{
Preconditions of emergence of large-span buildings in the world
}

\author{
Elena Sysoeva ${ }^{1, *}$ \\ ${ }^{1}$ Moscow State University of Civil Engineering, Department of Design of Buildings and Structures, \\ Yaroslavskoe sh. 26, 129337 Moscow, Russia
}

\begin{abstract}
The article is devoted to the design and construction of Olympic facilities in the world, preconditions of the emergence of largespan buildings and structures. Every example includes information about the building structural systems, names of architects and engineers, some interesting facts about the construction technology. There is a review about several Olympic stadiums in the world, including the stadium "Friendship", Small Olympic Palace in Rome, indoor ice arena Makomanai in Sapporo (Japan), the Olympic stadium in Montreal, Kanteerava Indoor Stadium (India) etc. The article includes opinions of scientists on the development of long-span structures in the coming years.
\end{abstract}

\section{Introduction}

Public buildings are often architectural dominants of major cities. Bright expression and the whole image of residential areas attract tourists from all over the world. The design and architecture of public buildings will be given significant attention. Building material and the coating form of such buildings can play an important visual role in the perception of the building by any person. Before the end of the eighteenth century the main construction kinds of material were stone, wood and ancient concrete but from the end of the twentieth century besides reinforced concrete and glued wood synthetic material have been often used, such as ETFE, for example.

In ancient times there was a need in the construction of arenas for performances of gladiators (for example, The Coliseum) and a sport competition (the first athletic building was built by architect Leonid in the fourth century BC "Leonidaion"). But due to the prohibition of gladiatorial combats and the cessation of the sports of the Olympics basically religious buildings had been built until 1896 (churches, temples, cathedrals, etc.). And only at the end of the nineteenth century a new surge of the Olympic movement began. It led to the need of the construction of buildings with long spans. To this moment, in addition to the need for such buildings, there are new great opportunities - new building material reinforced concrete (the invention of Monier in 1867).

An opening of a new building material (reinforced concrete), development of the theory of reinforced concrete as a science, the engineering school in the world which led to the

\footnotetext{
* Corresponding author: sev4279@yandex.ru
} 
emergence of a galaxy of scientists all around the world, became the prerequisites for the formation of thin-walled reinforced concrete long-span buildings.

\section{The modern Olympics}

The revival of modern Olympic summer games at the end of the nineteenth century and in 28 years the winter Olympic Games has led to the need of construction of buildings with large unsupported spaces for stadiums, swimming pools, race tracks, etc. Scientists state that since 1960s Olympic Games are reviving the continued international interest in the creation of large span buildings [1].

The tradition of holding of the Olympic Games leads to the necessity of designing and building of stadiums, concert halls and other large-span complexes in the cities to host the Olympics. From 1955 to 1956 it was the designing and construction of "Central stadium named after V. I. Lenin" (now a sport hall "Druzhba") with dimensions in plan 85x85 m, height $18 \mathrm{~m}$ and a capacity of 4,000 seats. The central part of the roof is ribbed thin concrete coating supported by 28 reinforced concrete panels with complex geometric shapes (Fig. 1) [2].

The authors of the project were architects A. V. Vlasov, I. E. Rozhin, and A. F. Boars, N. N. Ullas, and engineers V. N. Nasonov, N. M. Reznikov, V. P. Polikarpov [4]. The sports complex was built in record time of 450 days. By 1980, the building had undergone renovations to prepare for the Moscow Olympics.

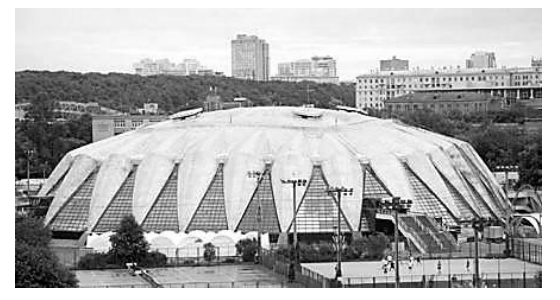

Fig. 1. The «Druzhba» Multipurpose Arena (photo credit: http://www.vashdosug.ru/msk/concert/place/7664/).

But if the first Games was held at the stadium Panathinaikos restored in the midnineteenth century and for the next fourteen games only opened stadiums were built, for the Olympic games in Rome in 1960 an Italian architect and engineer Luigi Nervi [3] and his friend and architect Annibale Vitellozzi Small and Large Olympic stadiums in Rome with coating of ribbed concrete domes were designed. During the construction of Small Olympic Hall (Fig. 2) Nervi used a caisson cover, reinforced with thin steel mesh. The diameter of the dome is $61 \mathrm{~m}$.

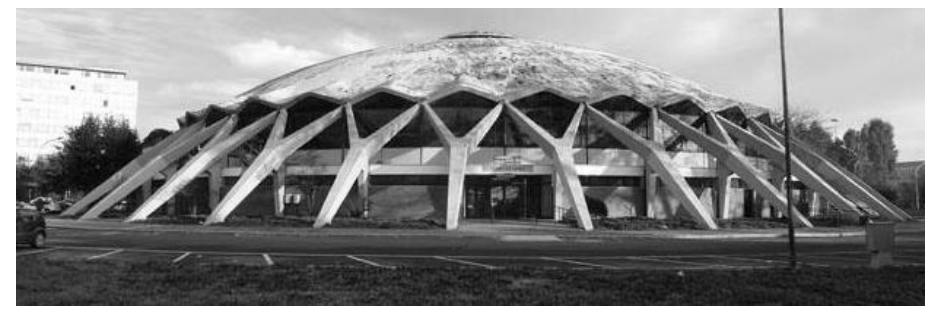

Fig. 2. Small Olympic Hall, Rome, Italy (photo credit://www.nashi-progulki.ru). 
In 1972 indoor ice arena Makomanai located in Sapporo (Japan) was built. Its capacity is 6020 seats (Fig. 3, 4). The diameter of the building is 109 meters. The building structural system consists of 48 concrete columns supporting a steel frame, which is a support for 24 metal trusses. «The rink was surrounded plastic fence to give the spectators an unobstructed view of the action at all times» [4].

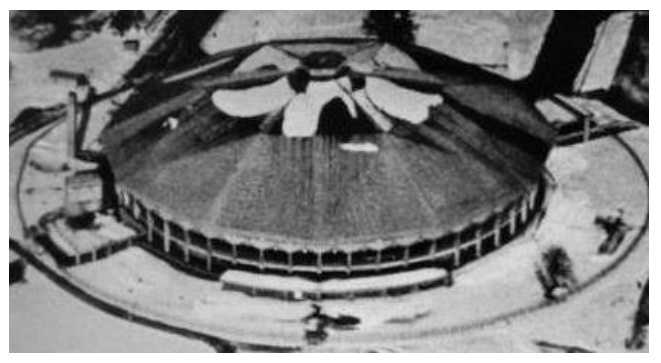

Fig. 3. Makomanai Sekisui Heim Ice Arena, Sapporo, Japan.

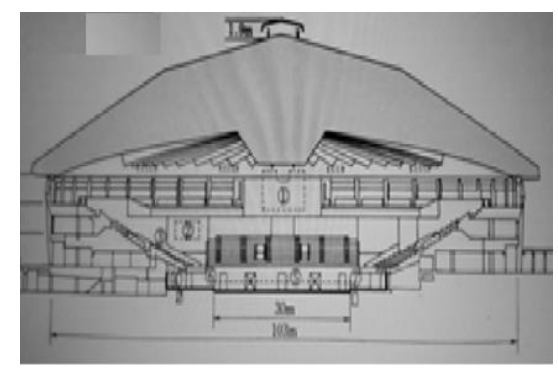

Fig. 4. Cross sectional view.

In 1976, architect Roger Taillibert and his team the Olympic stadium in Montreal was designed. The stadium consisted of a slanted tower (at that time the highest in the world) with a retractable membrane roof (Fig. 5).

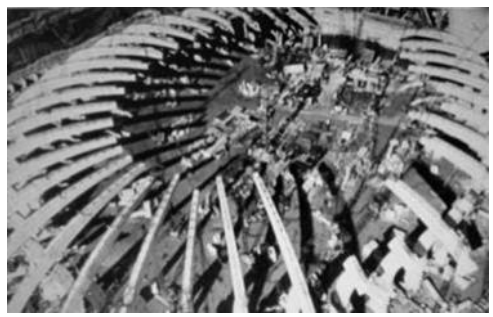

Fig. 5. Concrete frame of the Olympic Stadium in Montreal.

It was the stadium which was designed and made of only concrete and consisted of 12000 prefabricated elements, «adjusted and assembled to the others with the utmost precision $»[4]$.

Building structural system was created of 34 reinforced concrete curved consoles connected with a central concrete ring creating a single monolithic system. Technical equipment was installed on two floors. A large part of the lighting equipment was installed on the ground floor. The second floor is occupied by technical ventilation systems. More than 10,000 workers participated in the construction of this unique building, constantly 
working from August design is the Stadium's Tower. It is 165 meters high and has a 45 degree incline.

For the Olympic Games in 1980 one of the largest stadiums in the world "Olympic" at Prospect Mira in Moscow (Russia) was built (Fig. 6).

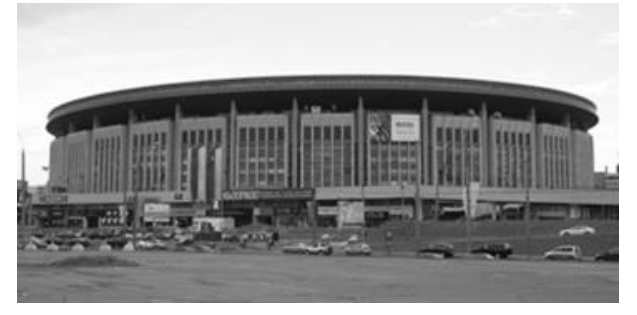

Fig. 6. Olympic sport Stadium "Olympic" (photo credit: https://ru.wikipedia.org/wiki).

Architects of the project were M. V. Posokhin, B. I. Thor, HP, Aranauskas and engineers Lvov Y. P., Chertkov L. I., Eremeev P. G., Trofimov V. I. The design of the coating is a metal hanging membrane with positive curvature Gassoway with the sag of $12.5 \mathrm{~m}$ and $5 \mathrm{~mm}$ thick, dimensions in plan are 224x183M. Membrane design has been supported by 64 steel wire ropes. The hall's capacity is 45000 [1].

Kanteerava Indoor Stadium (Fig. 7) is an indoor sporting arena in Bangalore, India (1998). The capacity of the arena is 4,000 people. Elliptical structural system consists of 120 precast folded plates spanning between a tension ring at its base and a compression ring at its crown [1].

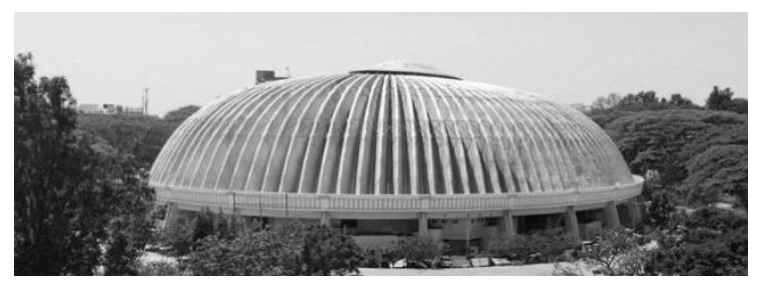

Fig. 7. Kanteerava Indoor Stadium, Bangalore, India.

One of the most interesting works of an engineer Christiansen was the Seattle Kingdome (completed in 1976 and demolished in 2000, Fig. 8). The building construction consists of 40 triangle hyperboloid paraboloid segments, stiffened by ribs. Its maximum span is $201,5 \mathrm{~m}$.

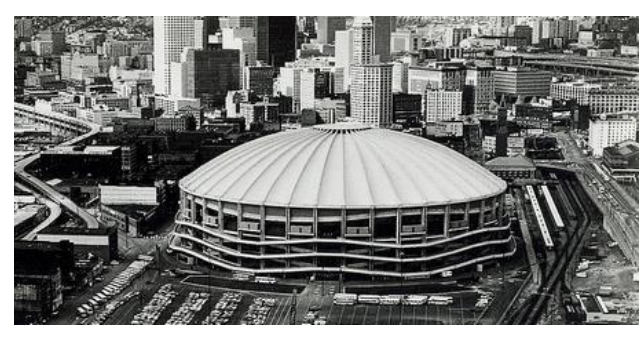

Fig. 8. Kingdome, Seattle, 1976.

Indoor sports arena in Raleigh (North Carolina, USA) has a capacity of 5500 seats (Fig. 9). The building is covered hanging saddle-like shape. The basis for the structural system of the arena in Raleigh is the two concrete arch cross sections which are inclined to the horizon at an angle $22^{\circ}$. Arches attached to the cables with a pitch of $1.8 \mathrm{~m}$ for the formation of saddle-shaped rigid surface. 


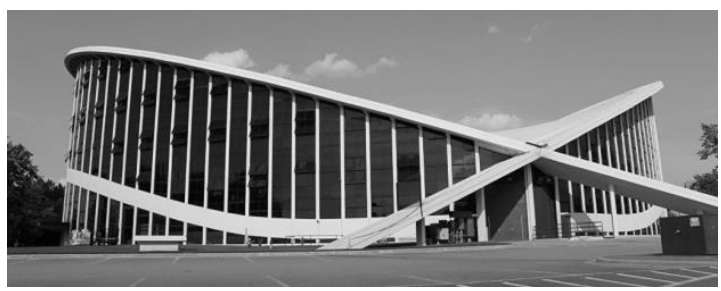

Fig. 9. Sports arena in Raleigh, North Carolina, USA.

Rungnado 1st of May Stadium is located on a sandy island Ninnada in Pyongyang (North Korea). The stadium capacity is 150,000 spectators. The construction finished in 1989 (Fig. 10).

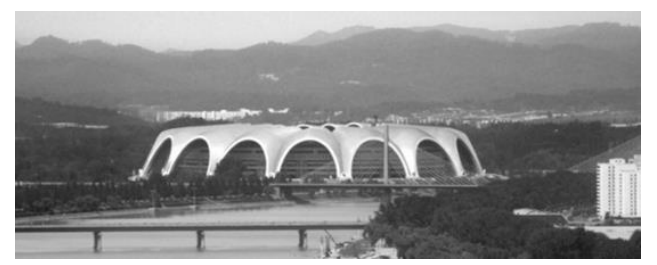

Fig. 10. Rungnado 1st of May Stadium (North Korea).

Concrete covering of the stadium consists of 16 shell segments. Building has a height of $60 \mathrm{~m}$. The construction lasted about 2,5 years.

\section{The prospects for further development}

For many decades, designers and architects have been looking for the perfect geometry, shape and static conditions, which correspond to the most profitable use of the material and the smallest expenditure of labor. Calculator engineers are engaging of the development of numerical methods for detailed qualitative and numerical analysis of the stress-strain state of an arbitrary shell. All the efforts of scientists and professionals of all areas in the structural design of long-span public buildings aimed at finding new opportunities to cover the unsupported spaces $[5,6]$. But if in the previous century the construction of buildings of this type was related to preparation for the Olympics, the emergence of theatres, circuses, temples, nowadays large spans are needed to create a comfortable stay in undeveloped areas with an unfavourable climate, comfortable work of builders in areas with very low or very high temperatures, for the frame tent and pneumatic building used for sports, shopping facilities, etc. Therefore, the attention of designers is drawn to new structural types of longspan buildings and new numerical methods for their calculation.

\section{References}

1. J.F. Abel, Fifty Years of Progress for Shell and Spatial Structures, 485 (2011)

2. P.G. Eremeev, The modern design of coverings over the stands of stadiums (Publishing house ASV, Moscow, 2015).

3. L. Nervi, Proceedings of IASS 2, 19 (1969)

4. Official Report of the XIth Olympic Winter Games, Sapporo (1972)

5. M.S. Tupolev, Proceedings of IASS 1, 747 (1969)

6. G.A. Karavaev, Proceedings of IASS 2, 403 (1969) 